\title{
Immediate effects of hip mobilization with movement in patients with hip osteoarthritis: a randomised controlled trial
}

\begin{abstract}
Background: Mobilization with movement (MWM) has been shown to reduce pain, increase range of motion (ROM) and physical function in a range of different musculoskeletal disorders. Despite this evidence, there is a lack of studies evaluating the effects of MWM for hip osteoarthritis (OA).

Objectives: To determine the immediate effects of MWM on pain, ROM and functional performance in patients with hip OA.

Design: Randomized controlled trial with immediate follow-up.

Method: Forty consenting patients (mean age $78 \pm 6$ years; $54 \%$ female) satisfied the eligibility criteria. All participants completed the study. Two forms of MWM techniques $(n=20)$ or a simulated MWM (sham) $(n=20)$ were applied. Primary outcomes: pain recorded by numerical rating scale (NRS). Secondary outcomes: hip flexion and internal rotation ROM, and physical performance (timed up and go, sit to stand, and 40m self placed walk test) were assessed before and after the intervention.

Results: For the MWM group, pain decreased by 2 points on the NRS, hip flexion increased by $12.2^{\circ}$, internal rotation by $4.4^{\circ}$, and functional tests were also improved with clinically relevant effects following the MWM. There were no significant changes in the sham group for any outcome variable.

Conclusions: Pain, hip flexion ROM and physical performance immediately improved after the application of MWM in elderly patients suffering hip OA. The observed immediate changes were of clinical relevance. Future studies are required to determine the long-term effects of this intervention.
\end{abstract}


Registered: ClinicalTrials.gov, NCT02390336

Key words: Manual Therapy; Osteoarthritis hip; Pain; Range of motion, Articular. 


\section{Immediate effects of hip mobilization with movement in patients with hip osteoarthritis: a randomised controlled trial}

\section{$\underline{\text { INTRODUCTION }}$}

Osteoarthritis $(\mathrm{OA})$ is a common degenerative joint disease that causes substantial musculoskeletal pain and disability (Bennell, 2013). The global agestandardised prevalence of symptomatic radiographically confirmed hip OA is $0.85 \%$, being more common in females, and increasing with age. Hence the burden of hip OA is likely to rise, as globally the number of people aged over 60 years is expected to increase to $33 \%$ by 2030 (Croft, 2005; Wright et al., 2011).

The characteristic features of hip OA are loss of articular cartilage, joint space narrowing, and capsule contracture and fibrosis (Sokolove and Lepus, 2013). These changes will often result in pain, impaired mobility, and limitation in activities of daily living (Steultjens et al., 2000), although change in pain is potentially more important for prognosis (van Dijk et al., 2010). Physical examination reveals joint pain during activity such as stair climbing, sit to stand, and walking, as well as reduced hip flexion and internal rotation range of motion (ROM) (Altman et al., 1991; Birrell et al., 2001; Wylde et al., 2014).

Clinical practice guidelines recommend manual therapy combined with exercise as part of the management of hip OA (Hochberg et al., 2012; National Institute for Clinical Excellence, 2014). This is despite contradictory evidence, with one study showing that manual therapy is an effective treatment in the long-term management of hip OA (Abbott et al., 2013) but not when combined with exercise in another (Bennell 
et al., 2014). One explanation may be that hip OA responds differently to different forms of manual therapy. One form of manual therapy for the hip is mobilization with movement (MWM) (Mulligan, 1989; Hing et al., 2015). MWM combines an accessory glide force with an active or passive movement. The purpose is to eliminate pain during movement enabling a greater range and improved function. Despite positive results in some painful joint conditions (shoulder, elbow, and ankle) and preliminary results from a case series of patients with knee OA (Abbott, 2001; Collins et al., 2004; Dimitrova, 2008; Anap, 2012; Djordjevic et al., 2012; Takasaki et al., 2013), the effects of MWM on the hip have not been investigated in isolation. Thus, there is a need for further research to confirm the effectiveness of manual therapy intervention in hip OA (French et al., 2011). Due to the conflicting evidence regarding the efficacy of manual therapy for hip OA (Abbott et al., 2013; Bennell et al., 2014), new studies are required to determine whether alternate forms of manual therapy (such as MWM), that have not been investigated in isolation may be effective in hip OA. In this regard a preliminary step may be to investigate the immediate effects of specific manual therapy techniques such as MWM. Techniques shown to produce immediate effects can then be compared in randomized controlled trials with long-term follow up.

Therefore, the primary purpose of this study was to determine the immediate effects of a single session of MWM on hip pain in people with hip OA. The secondary objective was to evaluate the immediate effects of MWM on hip ROM and physical performance in these subjects. We hypothesized that a single session of hip MWM would reduce pain, increase ROM, and improve function in people with hip OA. 


\section{MATERIALS AND METHODS}

Study design

A double blind randomized placebo controlled trial was conducted (registered with ClinicalTrials.gov, NCT02390336). The study was carried out according to CONSORT guidelines.

\section{$\underline{\text { Participants }}$}

The study sample consisted of a sample of convenience of volunteers residing in one of two retirement homes in $\mathrm{XXX}(\mathrm{XXX})$. The inclusion criteria were: aged over 65 years, and clinical criteria of OA of the hip, established by the American College of Rheumatology (Altman et al., 1991). Subjects were excluded from the study if they had received lower extremity surgery in the previous 6 months, rheumatoid arthritis, uncontrolled hypertension, mobility aid during walking, a primary neurogenic disorder, advanced osteoporosis, previous physiotherapy treatment to the hip, or inability to understand the instructions and complete the study assessments.

Subjects were randomly allocated into one of two groups by the Research Randomizer (Version 4.0) computer software: experimental (MWM group) and placebo (sham intervention). Only the first author was aware of subject group allocation. A blinded examiner carried out measurements with subjects' blind to their intervention.

\section{Ethical approval statement}

The study received ethical approval from the Ethics Committee of the XXX XXX XXX XXX XXX XXX XXX (Reference number 1455/2014). Patients provided written and informed consent to participate in this study. 


\section{Interventions}

MWM and the sham intervention were carried out by the first author, blind to the measurements, who received training in the Mulligan Concept and had 3 years clinical experience.

In the experimental group two forms of MWM were applied. The first, a hip flexion MWM was carried out with the subject supine and the physical therapist standing next to the subject. A manual therapy belt was looped around the therapist's pelvis and the subject's thigh contacting the medial side of the participant's upper thigh closest to the joint line. The belt was positioned such that it was always perpendicular to the participant's thigh (Hing et al., 2015). The therapist supported the subject's leg, while also stabilizing their pelvis via the ilium. The subject's hip was moved passive into hip flexion to the maximum pain-free range. Three sets of 10 repetitions were applied, with a one minute rest interval between each set (Fig. 1). Following this, a hip internal rotation MWM was performed (Fig. 2). The procedure was the same as for hip flexion except that passive internal rotation was the movement applied with the hip as close as possible to $90^{\circ}$ flexion. The physical therapist could adapt the angle and strength of the accessory mobilization to maximize ROM response and decrease pain. A towel was placed at the site of belt contact to reduce discomfort (Figs. 1 and 2) (Mulligan, 2010). The order of technique application was the same for all subjects.

\section{Figure 1 and Figure 2 here}

In the placebo group, the investigator performed a simulated MWM technique. The positioning of the patient and the physical therapist were the same as for the MWM 
procedure, however, no force was applied with the belt and no repeated movement of passive hip flexion or internal rotation carried out (Abbott et al., 2013). The positions of hip flexion and internal rotation were maintained for 10 seconds and repeated 3 series.

\section{Outcome measures}

Outcome measures were evaluated by a blinded examiner in all subjects prior-to and five-minutes after the intervention. Measures included pain intensity, hip flexion and internal rotation ROM, and functional tests. Subjects had no previous experience of manual therapy and hence were naïve to the technique used, and were thus blind to the intervention. To determine intra-observer reliability of the outcome measures, two evaluations where made 72 hours apart in 10 individuals, with the same characteristics of the study sample. The intraclass correlation coefficient (ICC) and minimal detectable change (MDC) with the $95 \%$ confidence interval (CI) of all outcomes were obtained.

\section{Primary outcome}

The Numeric Rating Pain Scale (NRPS) was used to measure resting pain intensity. In the preliminary intra-observer reliability study the ICC value obtained for this measurement was $0.89(95 \% \mathrm{CI}=0.63-0.97)$ and $\mathrm{MDC} 0.83(95 \% \mathrm{CI}=-0.83-2.50)$.

\section{Secondary outcomes}

Hip flexion and internal rotation ROM was recorded using a universal goniometer, whose validity has been established (Prather et al., 2010; Pua et al., 2008). In the preliminary intra-observer reliability study the ICC value obtained for this measurement was $0.99(95 \% \mathrm{CI}=0.98-0.99)$, and $\mathrm{MDC} 1.11^{\circ}(95 \% \mathrm{CI}=-1.11-3.60)$ 
for hip flexion and for hip internal rotation the ICC was $0.99(95 \% \mathrm{CI}=0.96-0.99)$ and $\operatorname{MDC} 0.55^{\circ}(95 \% \mathrm{CI}=-0.55-1.94)$.

The Timed Up and Go (TUG) test simulates some functional activities of daily living (sitting to standing, walking, and sitting down) (Bennell et al., 2011). In the preliminary reliability study the ICC value obtained for this measurement was 0.99 $(95 \% \mathrm{CI}=0.95-0.99)$ and $\mathrm{MDC} 1.11 \mathrm{~s}(95 \% \mathrm{CI}=-1.11-3.33)$.

The 30s Chair Stand (CS) test is a valid test that assesses the function and strength of the lower limbs (Bennell et al., 2011; Gill and McBurney, 2008). In our preliminary reliability study the ICC value obtained for this measurement was 0.99 $(95 \% \mathrm{CI}=0.97-0.99)$ and $\mathrm{MDC} 0.55$ repetitions $(95 \% \mathrm{CI}=-0.55-1.66)$.

The 40m Self Placed Walk (SPW) test is a valid functional test (Bennell et al., 2011; Kennedy et al., 2005). In the preliminary reliability study the ICC value obtained for this measurement was $0.99(95 \% \mathrm{CI}=0.98-0.99)$ and $\mathrm{MDC} 1.66 \mathrm{~s}(95 \% \mathrm{CI}=-1.66-$ 4.71).

\section{$\underline{\text { Sample size determination }}$}

The sample size was calculated using Ene 3.0 software (GlaxoSmithKline, Autonomic University of Barcelona, Spain). The calculations were based on detecting differences of 2.0 units in the NPRS, considered as the minimum clinical important difference (MCID) (Farrar et al., 2001), assuming a standard deviation of 1.7 (based on pilot data), an $\alpha$ of $0.05, \beta$ of $90 \%$, and a 2 -tailed t-test. The estimated sample size was calculated to be at least 17 subjects in each group. The sample was increased to 20 subjects in each group to allow a drop out of $15 \%$. 


\section{$\underline{\text { Statistical analyses }}$}

Mean, standard deviations and/or 95\% confidence intervals were calculated for quantitative variables. The Kolmogorov-Smirnov test was used to assess for the normal distribution of quantitative data ( $p>0.05$ for all variables). Between groups comparisons of baseline clinical and demographic variables were performed using independent Student t-tests and $\chi 2$ tests for continuous and categorical data, respectively. A two-way analysis of variance (ANOVA) was used to investigate the differences in outcomes with time (pre- and post-treatment) as the within-subjects factor and group (MWM, sham) as the between-subjects factor. The hypothesis of interest was the Group by Time interaction. The effect size was also calculated, with standardized mean score differences (SMD) to estimate the magnitude of the differences within and between groups (SMD classification: $0.20-0.49$, small; $0.50-0.79$, moderate; 0.80 or higher, large) (Cohen, 1988). A p-value <0.05 was considered statistically significant. SPSS statistical software, version 21.0 was used for all statistical analyses.

\section{RESULTS}

Fifty-five consecutive patients with hip pain were screened for eligibility criteria. Forty patients (mean \pm SD age: $78 \pm 6$ years; $54 \%$ female) satisfied the eligibility criteria, agreed to participate, and were randomized into the MWM group ( $n=20)$ or sham group $(n=20)$. The reasons for ineligibility are reported in Fig. 3, which provides a flow diagram of patient recruitment and retention. Demographics and baseline data were similar for all variables between groups (Table 1).

Figure 3 and Table 1 and 2 here 
Table 2 provides baseline and post-intervention data as well as within-group and between-groups differences for hip pain, hip ROM and functional tests. A two way ANOVA revealed a significant Group by Time interaction for the intensity of pain $(\mathrm{F}=29.06, \mathrm{P}<0.01) .16$ patients receiving $\mathrm{MWM}$, in contrast to 2 patients receiving sham mobilisation, experienced a decrease in hip pain more than the MDC of 0.83 . A significant Group by Time interaction was detected for hip flexion $(\mathrm{F}=74.13 ; \mathrm{P}<0.01)$ and hip internal rotation $(\mathrm{F}=18.38 ; \mathrm{P}<0.01) \mathrm{ROM}$. For hip flexion, all patients receiving MWM and 11 patients receiving sham mobilisation, experienced an increase in ROM more than the MDC of $1.11^{\circ}$. For hip internal rotation, 16 patients receiving MWM and 4 patients receiving sham mobilisation, experienced an increase in ROM more than the MDC of $0.55^{\circ}$. An ANOVA also revealed a significant Group by Time interaction for all functional tests (TUG: $\mathrm{F}=10.00, \mathrm{P}<0.01 ; \mathrm{CS}: \mathrm{F}=29.46, \mathrm{P}<0.01$; SPW: $\mathrm{F}=23.80$, $\mathrm{P}<0.01$ ). For functional tests, 15 patients receiving $\mathrm{MWM}$ and 3 patients receiving sham mobilisation, experienced a reduction in TUG more than the MDC. For SPW, 18 patients receiving MWM and 7 patients receiving sham mobilisation, experienced a reduction in SPW more than the MDC. For CS, 17 patients receiving MWM and 4 patients receiving sham mobilisation, experienced an increase in repetitions more than the MDC.

\section{DISCUSSION}

This is the first randomized controlled trial to assess the effectiveness of MWM, when applied alone, on pain, ROM and function in subjects with hip OA. Hip pain decreased immediately after a single session of MWM when compared to a sham 
technique in this sample of elderly subjects with hip OA. Furthermore, maximal hip flexion and internal rotation ROM and functional performance improved after MWM of the hip, which confirms the a-priori hypothesis. It should be recognized that the difference between groups for the change in intensity of pain (2.0 points) exceeds the MCID reported by Farrar et al (2001), and is more than the MDC calculated from this study's preliminary reliability study. Moreover, all functional tests also achieved between-group differences higher than the MCID for the TUG test of 1.4 (Wright et al., 2011); CS test of 1.6 repetitions (Gill and McBurney, 2008); SPW test of 4.0s (Wright et al., 2011) in a similar population of people suffering from hip OA. For hip ROM change scores, a greater proportion of people in the MWM compared to sham group improved more than the MDC values obtained from our preliminary reliability study. Despite this finding, not all subjects improved. This is consistent with the Mulligan Concept treatment approach, where a trial MWM is performed and if pain or ROM improves, this would be an indication to continue with the MWM (Hing et al., 2015). The clinical applicability of these results is of interest, since pain and functionality are two of the main complaints of the elderly suffering OA of the hip (van Baar et al., 1998; Stratford and Kennedy, 2006).

Although no previous study has investigated the effects of MWM on the hip in isolation, one previous study used a combination of MWM with trunk stabilization exercises and reported a similar decrease in VAS pain scores to our study (Nam et al., 2013). Other studies have also reported on the effect of manual therapies for hip OA. Hando et al (2012) reported a similar reduction in pain and a greater increase in flexion $\left(>25^{\circ}\right)$ and internal rotation $\left(>10^{\circ}\right)$ ROM than those found in the present study. In that study, manual therapy was composed of muscle stretch and articular movements combined with exercises given over an 8-week period. In a degenerative condition such 
as hip OA, it is plausible that a single session could achieve a clinically relevant reduction in pain but not achieve increases in ROM, as was the case of the internal rotation movement in the current study. This is consistent with MWM applied to a case series of people with knee OA (Takasaki et al., 2013). Perhaps more treatment over a longer period is required to increase ROM, as previously documented in OA of the knee (Taylor et al., 2014), although the results of the study of Hando et al (2012) must be interpreted with caution due to the absence of a control group and the lower age of the sample with respect to our sample.

There is some evidence that different manual therapy techniques have different effects on hip OA. Bennell et al (2014) reported no benefit when compared to a sham for 10 sessions of exercise and manual therapy (hip thrust manipulation, muscle stretching and massage) on pain and function. This is in contrast to another study where 4 to 12 sessions of manual therapy and exercise had beneficial effects in hip OA (Hoeksma et al., 2004), as well as the current study's findings. It is beyond the scope of this study to identify why MWM may be of greater benefit to Kaltenborn hip thrust techniques. One potential explanation is the combination of accessory movement with active movement that occurs in MWM but not in Kaltenborn thrust. Whatever the explanation, the immediate positive effect of MWM indicates scope for future studies to investigate the long-term effects of this form of manual therapy.

The present study showed that a single session of MWM improves physical function evaluated using three reliable and validated tests (TUG, CS, SPW). These tests assess different aspects of disability associated with hip OA (Stratford and Kennedy, 2006), including basic functional mobility, strength, balance, and agility. In contrast to our results, the application of nine manual therapy sessions in a younger sample of subjects with hip OA had no effect on functional outcome measures (Abbott et al., 
2013). Our results could be due to the advanced age of our sample, perhaps with different baseline values for functional tests compared to a younger population, or perhaps due to differences in manual therapy intervention. The results from the present study highlight the importance of further research in this area.

The mechanism of action for MWM to improve musculoskeletal complaints is not known. It has been suggested that MWM alters a positional fault of the joint (Vicenzino et al., 2007), but this is unlikely in the hip joint, which has such congruent joint surfaces. Alternatively, it has been suggested that MWM might provide a stretching effect on the joint capsules and muscles, thus restoring normal arthrokinematics or may induce pain inhibition and improved motor control (Hing et al., 2015). Neurophysiological mechanisms associated with MWM include changes to the descending pain inhibitory system (Paungmali et al., 2004) as well as potentially central pain processing mechanisms (Sterling and Vicenzino, 2011). It is possible that MWM reduces pain by stimulation of joint mechanoreceptors, which subsequently inhibits nociceptive stimuli (Paungmali et al., 2003). In addition to these neurophysiological and biomechanical effect, the repeated motion of MWM, might alter the concentrations of anti-inflammatory mediators in the joint, which might consequently inhibit nociceptors (Sambajon et al., 2003). Finally, other possible mechanisms include psychological effects such as a reduction in fear avoidance associated with movement (Vicenzino et al., 2011).

\section{$\underline{\text { Study limitations }}$}

There are a number of potential limitations to our study. First, patients were not selected on the basis of positive response to MWM, which is a normal requirement to apply a MWM. Secondly, only immediate effects were evaluated, although this kind of 
research design may help develop future research protocols. Thirdly, only one session of treatment was applied, which is insufficient when treating a chronic condition such as hip OA. Fourth, only one clinician provided both interventions and only one therapy was applied, without any combination with other treatments, which limit the generalizability of the results, mainly with respect to MWM clinical effects. Future studies should include medium and long-term follow-ups and a longer treatment period, more treating clinicians with different expertise, and multimodal therapeutic approaches.

\section{CONCLUSIONS}

This study showed that pain immediately decreased, hip flexion and internal rotation ROM and physical function improved after a single session of hip MWM in elderly subjects suffering hip OA. Although the observed immediate changes are greater than the MDC and previous reports for MCID, more research is necessary to determine long-term efficacy. 


\section{REFERENCES}

Abbott JH. Mobilization with movement applied to the elbow affects shoulder range of movement in subjects with lateral epicondylalgia. Man Ther 2001; 6: 170-7.

Abbott JH, Robertson MC, Chapple C, Pinto D, Wright AA, Leon de la Barra S, et al. Manual therapy, exercise therapy, or both, in addition to usual care, for osteoarthritis of the hip or knee: a randomized controlled trial. 1: clinical effectiveness. Osteoarthritis Cartilage 2013; 21: 525-34.

Altman R, Alarcón G, Appelrouth D, Bloch D, Borenstein D, Brandt K, et al. The American College of Rheumatology criteria for the classification and reporting of osteoarthritis of the hip. Arthritis Rheum 1991; 34: 505-14.

Anap D. Mobilization with Movement Technique as an Adjunct to Conventional Physiotherapy in Treatment of Chronic Lateral Epicondylits-A Comparative Study. J Nov Physiother 2012; 2: 121.

Bennell K. Physiotherapy management of hip osteoarthritis. J Physiother 2013; 59: 14557.

Bennell K, Dobson F, Hinman R. Measures of physical performance assessments: SelfPaced Walk Test (SPWT), Stair Climb Test (SCT), Six-Minute Walk Test (6MWT), Chair Stand Test (CST), Timed Up \& Go (TUG), Sock Test, Lift and Carry Test (LCT), and Car Task. Arthritis Care Res (Hoboken) 2011; 63: S35070.

Bennell KL, Egerton T, Martin J, Abbott JH, Metcalf B, McManus F, et al. Effect of physical therapy on pain and function in patients with hip osteoarthritis: a randomized clinical trial. JAMA 2014; 311: 1987-97. 
Birrell F, Croft P, Cooper C, Hosie G, Macfarlane G, Silman A, et al. Predicting radiographic hip osteoarthritis from range of movement. Rheumatology (Oxford) 2001; 40: 506-12.

Cohen J. Statistical Power Analysis for the Behavioral Sciences. Hillsdale, NJ: Lawrence Erlbaum Associates Publishers, 1988.

Collins N, Teys P, Vicenzino B. The initial effects of a Mulligan's mobilization with movement technique on dorsiflexion and pain in subacute ankle sprains. Man Ther 2004; 9: 77-82.

Croft P. The epidemiology of osteoarthritis: Manchester and beyond. Rheumatology (Oxford) 2005; 44: iv27-iv32.

Dimitrova E. Efficacy of mobilizations with movement in patient with knee osteoarthritis. Sport Medicine Journal 2008; 16.

Djordjevic OC, Vukicevic D, Katunac L, Jovic S. Mobilization with movement and kinesiotaping compared with a supervised exercise program for painful shoulder: results of a clinical trial. J Manipulative Physiol Ther 2012; 35: 45463.

Farrar JT, Young JPJ, LaMoreaux L, Werth JL, Poole RM. Clinical importance of changes in chronic pain intensity measured on an 11-point numerical pain rating scale. Pain 2001; 94: 149-58.

French HP, Brennan A, White B, Cusack T. Manual therapy for osteoarthritis of the hip or knee - a systematic review. Man Ther 2011; 16: 109-17.

Gill S, McBurney H. Reliability of performance-based measures in people awaiting joint replacement surgery of the hip or knee. Physiother Res Int 2008; 13: 141 52. 
Hando BR, Gill NW, Walker MJ, Garber M. Short- and long-term clinical outcomes following a standardized protocol of orthopedic manual physical therapy and exercise in individuals with osteoarthritis of the hip: a case series. J Man Manip Ther 2012; 20: 192-200.

Hing W, Hall T, Rivett D, Vicenzino B, Mulligan B. The Mulligan Concept of manual therapy - Textbook of techniques. Sydney: Elsevier, 2015.

Hochberg MC, Altman RD, April KT, Benkhalti M, Guyatt G, McGowan J, et al. American College of Rheumatology 2012 recommendations for the use of nonpharmacologic and pharmacologic therapies in osteoarthritis of the hand, hip, and knee. Arthritis Care Res (Hoboken) 2012; 64: 465-474.

Hoeksma HL, Dekker J, Ronday HK, Heering A, van der Lubbe N, Vel C, et al. Comparison of manual therapy and exercise therapy in osteoarthritis of the hip: a randomized clinical trial. Arthritis Rheum 2004; 51: 722-9.

Kennedy DM, Stratford PW, Wessel J, Gollish JD, Penney D. Assessing stability and change of four performance measures: a longitudinal study evaluating outcome following total hip and knee arthroplasty. BMC Musculoskelet Disord 2005; 28: 3.

Mulligan B. Manual Therapy: Nags, Snags, Prp's, etc. Wellington: Plane View Services Ltd., 1989.

Mulligan B. Manual therapy : "NAGS", "SNAGS", "MWMs" ect. Wellington: Plane View Services Ltd., 2010.

Nam CW, Park SI, Yong MS, Kim YM. Effects of the MWM Technique Accompanied by Trunk Stabilization Exercises on Pain and Physical Dysfunctions Caused by Degenerative Osteoarthritis. J Phys Ther Sci 2013; 25: 1137-40. 
National Institute for Clinical Excellence. Osteoarthritis: Care and management in adults. London, UK: National Institute for Clinical Excellence, 2014.

Paungmali A, O'Leary S, Souvlis T, Vicenzino B. Hypoalgesic and sympathoexcitatory effects of mobilization with movement for lateral epicondylalgia. Phys Ther 2003; 83: 374-83.

Paungmali A, O'Leary S, Souvlis T, Vicenzino B. Naloxone fails to antagonize initial hypoalgesic effect of a manual therapy treatment for lateral epicondylalgia. J Manipulative Physiol Ther 2004; 27: 180-5.

Prather H, Harris-Hayes M, Hunt DM, Steger-May K, Mathew V, Clohisy JC. Reliability and agreement of hip range of motion and provocative physical examination tests in asymptomatic volunteers. PM R 2010; 2: 888-95.

Pua YH, Wrigley TV, Cowan SM, Bennell KL. Intrarater test-retest reliability of hip range of motion and hip muscle strength measurements in persons with hip osteoarthritis. Arch Phys Med Rehabil 2008; 89: 1146-54.

Sambajon VV, Cillo JEJ, Gassner RJ, Buckley MJ. The effects of mechanical strain on synovial fibroblasts. J Oral Maxillofac Surg 2003; 61: 707-12.

Sokolove J, Lepus CM. Role of inflammation in the pathogenesis of osteoarthritis: latest findings and interpretations. Ther Adv Musculoskelet Dis 2013; 5: 77-94.

Sterling M, Vicenzino B. Pain and sensory system impairments that may be amenable to Mobilisation with Movement. In: Vicenzino B, Hing W, Rivett D and Hall T, editors. Mobilisation with Movement: The art and the science. Chatswood: Elsevier, 2011: 86-92.

Steultjens MP, Dekker J, van Baar ME, Oostendorp RA, Bijlsma JW. Range of joint motion and disability in patients with osteoarthritis of the knee or hip. Rheumatology (Oxford) 2000; 39: 955-61. 
Stratford PW, Kennedy DM. Performance measures were necessary to obtain a complete picture of osteoarthritic patients. J Clin Epidemiol 2006; 59: 160-7.

Takasaki H, Hall T, Jull G. Immediate and short-term effects of Mulligan's mobilization with movement on knee pain and disability associated with knee osteoarthritis--a prospective case series. Physiother Theory Pract 2013; 29: 87-95.

Taylor AL, Wilken JM, Deyle GD, Gill NW. Knee extension and stiffness in osteoarthritic and normal knees: a videofluoroscopic analysis of the effect of a single session of manual therapy. J Orthop Sports Phys Ther 2014; 44: 273-82.

van Baar ME, Dekker J, Lemmens JA, Oostendorp RA, Bijlsma JW. Pain and disability in patients with osteoarthritis of hip or knee: the relationship with articular, kinesiological, and psychological characteristics. J Rheumatol 1998; 25: 125-33. van Dijk GM, Veenhof C, Spreeuwenberg P, Coene N, Burger BJ, van Schaardenburg D, et al. Prognosis of limitations in activities in osteoarthritis of the hip or knee: a 3-year cohort study. Arch Phys Med Rehabil 2010; 91: 58-66.

Vicenzino B, Hall T, Hing W, Rivett D. A new proposed model of the mechanisms of action of Mobilisation with Movement. In: Vicenzino B, Hall T, Hing W and Rivett D, editors. Mobilisation with Movement: The Art and the Science. London: Churchill Livingstone, 2011: 75-85.

Vicenzino B, Paungmali A, Teys P. Mulligan's mobilization-with-movement, positional faults and pain relief: current concepts from a critical review of literature. Man Ther 2007; 12: 98-108.

Wright AA, Cook CE, Flynn TW, Baxter GD, Abbott JH. Predictors of response to physical therapy intervention in patients with primary hip osteoarthritis. Phys Ther 2011; 91: 510-24. 
Wylde V, Lenguerrand E, Brunton L, Dieppe P, Gooberman-Hill R, Mann C, et al. Does measuring the range of motion of the hip and knee add to the assessment of disability in people undergoing joint replacement? Orthop Traumatol Surg Res 2014; 100: 183-186. 
TABLE 1. Demographic details for both groups

\begin{tabular}{cccc}
\hline Clinical features & MWM group $(\mathbf{n = 2 0})$ & Sham group $(\mathbf{n = 2 0})$ & Significance \\
\hline Gender (male/female) & $6 / 14$ & $8 / 12$ & $\mathrm{X}^{2}=0.440 ; \mathrm{p}=0.507$ \\
Age (years) & $78.3 \pm 6.1$ & $77.5 \pm 6.9$ & $\mathrm{t}=0.410 ; \mathrm{p}=0.684$ \\
Pain duration (months) & $24.6 \pm 22.9$ & $24.9 \pm 19.7$ & $\mathrm{t}=0.125 ; \mathrm{p}=0.901$ \\
Time since diagnosis (months) & $22.2 \pm 22.7$ & $23.9 \pm 19.8$ & $\mathrm{t}=-0.052 ; \mathrm{p}=0.959$ \\
BMI $\left(\mathbf{K g} / \mathbf{c m}^{\mathbf{2}}\right)$ & $24.9 \pm 4.2$ & $24.8 \pm 4.4$ & $\mathrm{t}=-0.252 ; \mathrm{p}=0.802$ \\
\hline
\end{tabular}

MWM: Mobilization-with-Movement; BMI: Body Mass Index.

Values are expressed as mean $\pm \mathrm{SD}$, except where otherwise indicated. There were no significant differences between groups ( $p>0.05$ ). 
TABLE 2. Baseline, final values, change scores, and effect sizes for pain, range of motion and functional outcomes

\begin{tabular}{|c|c|c|c|c|c|c|}
\hline Outcome Group & Baseline & End of Treatment & $\begin{array}{l}\text { Within-Group } \\
\text { Changes }\end{array}$ & $\begin{array}{l}\text { Within-Group } \\
\text { Effect Sizes }\end{array}$ & $\begin{array}{l}\text { Between-Group } \\
\text { Differences in } \\
\text { Change Scores }\end{array}$ & $\begin{array}{l}\text { Between-Group } \\
\text { Effect Sizes }\end{array}$ \\
\hline \multicolumn{7}{|l|}{ NPRS (0-10) } \\
\hline Sham & $4.1 \pm 1.2$ & $4.0 \pm 1.3$ & $0.1(-0.4,0.5)$ & 0.0 & $-2.0(-1.3,-2.5)$ & 1.9 \\
\hline MWM & $4.7 \pm 1.7$ & $2.7 \pm 1.4$ & $-2.0(-2.5,-1.4)$ & 1.2 & & \\
\hline \multicolumn{7}{|l|}{ Hip Flexion $\left(^{\circ}\right)$} \\
\hline Sham & $102.9 \pm 11.7$ & $104.2 \pm 11.3$ & $1.2(-3.0,0.6)$ & 0.1 & $11.0(13.7,8.2)$ & 3.0 \\
\hline MWM & $104.2 \pm 11.3$ & $116.4 \pm 10.2$ & $12.2(14.0,10.4)$ & 1.1 & & \\
\hline \multicolumn{7}{|l|}{ Hip Internal Rotation $\left({ }^{\circ}\right)$} \\
\hline Sham & $23.4 \pm 7.8$ & $23.3 \pm 7.2$ & $-0.1(-1.4,1.5)$ & 0.0 & $4.4(6.4,2.4)$ & 1.4 \\
\hline MWM & $25.1 \pm 7.2$ & $29.4 \pm 7.4$ & $4.4(5.8,2.9)$ & 0.6 & & \\
\hline \multicolumn{7}{|l|}{ TUG test (seconds) } \\
\hline Sham & $27.9 \pm 9.7$ & $28.8 \pm 11.0$ & $0.9(-0.4,2.1)$ & -0.1 & $-2.7(-0.8,-4.6)$ & 1.0 \\
\hline MWM & $24.7 \pm 13.9$ & $22.9 \pm 15.0$ & $-1.8(-0.6,-3.1)$ & 0.1 & & \\
\hline \multicolumn{7}{|l|}{ CS test (repetitions) } \\
\hline Sham & $6.4 \pm 2.7$ & $6.3 \pm 2.4$ & $-0.1(-0.6 .0 .4)$ & -0.0 & $2.0(2.8,1.1)$ & 1.7 \\
\hline MWM & $6.4 \pm 1.6$ & $8.3 \pm 2.0$ & $1.9(2.4,1.4)$ & 1.0 & & \\
\hline \multicolumn{7}{|l|}{ SPW Test (seconds) } \\
\hline Sham & $70.8 \pm 15.1$ & $73.0 \pm 17.2$ & $2.2(-5.5,1.1)$ & -0.1 & $-11.2(-6.7,-15.7)$ & 1.5 \\
\hline MWM & $70.6 \pm 23.4$ & $61.6 \pm 20.5$ & $-9.0(5.7,12.3)$ & 0.4 & & \\
\hline
\end{tabular}

VAS: Visual Analogue Scale; TUG: Time Up \& Go; CS: 30 seconds Chair Stand; SPW: 40m Self Placed Walk; MWM: Mobilization-WithMovement.

Values are expressed as mean \pm SD for baseline and final means and as mean (95\% confidence interval) for within-group and between-group change scores (higher values indicate greater movement, greater functionality and lower level of pain). 


\section{Figure legends}

Fig. 1: Hip flexion mobilization-with-movement technique.

Fig. 2: Internal rotation mobilization-with-movement technique.

Fig. 3: Flow chart of the study. 